\title{
Combined Treatment of Carbon Monoxide and Chitosan Reduced Peach Fruit Browning and Softening During Cold Storage
}

\author{
Zhang Shaoying*, Zhu Lishun, Dong Xuyuan \\ College of Food Science, Shanxi Normal University, Linfen, China
}

Email address:

zsynew@163.com (Zhang Shaoying)

To cite this article:

Zhang Shaoying, Zhu Lishun, Dong Xuyuan. Combined Treatment of Carbon Monoxide and Chitosan Reduced Peach Fruit Browning and Softening During Cold Storage. International Journal of Nutrition and Food Sciences. Vol. 4, No. 4, 2015, pp. 477-482. doi: 10.11648/j.ijnfs.20150404.19

\begin{abstract}
The effects of postharvest application of chitosan and carbon monoxide (CO) on fruit browning and softening during cold storage $\left(8{ }^{\circ} \mathrm{C}\right)$ were evaluated. $\mathrm{CO}(10 \mu \mathrm{mol} / \mathrm{L})$ significantly delayed the internal browning of peach fruit, and the effect was enhanced in combination with chitosan $(1 \%, \mathrm{w} / \mathrm{w})$. Further studies showed that treatment with $\mathrm{CO}$ and chitosan reduced the increase of PPO and POD activities, maintained PAL activity and total phenoilics content at a higher level. Moreover, it also reduced fruit tissue softening by retarded the increase of PE, PG activities and water soluble pectin content, inhibited the decline of flesh firmness as well as sustained the balance of PG and PE activities, improved the ability of chilling injury tolerance. Therefore, peaches treated with chitosan and $\mathrm{CO}$ obviously delayed the fruit browning and softening during cold storage, and it indicates that combined treatment with chitosan and $\mathrm{CO}$ can be effective in reducing browning and softening of peach fruit and inhibited chilling injury during cold storage.
\end{abstract}

Keywords: Peach, CO, Chitosan, Browning, Softening, Cold Storage

\section{Introduction}

Peach is one of the most popular fruit in the world because of its high nutrient level and pleasant flavor. Peaches ripen in summer, and its respiratory metabolism is strong after harvest, which lead to soften, browning and decay quickly at ambient temperature $[1,2]$. Cold storage remains the main method to slow the product deterioration in terms of consumer perception and nutritional value. However, low temperature results in chilling injury symptoms, manifested as mealy (soft and dry, with lack of juice) or leathered flesh (hard textured, with no juice), with/without browning and bleeding in the flesh) in some peach cultivars during or after cold storage [3] and these influence its commercial value and economic benefit. Chemical treatments have been used to delay fruit senescence and prolong postharvest shelf life. However, the use of chemicals has been minimized for food safety and environmental reasons. Many physical methods including modified atmosphere packaging, heat and UV-C pretreatments, are being extensively studied as substitutes for the current chemical methods in commercial applications [4-6].

Chitosan and its derivatives like oligochitosan, have been reported to control postharvest diseases effectively. Chitosan is safe, nontoxic, biocompatible, and biodegradable natural alkaline polysaccharide derived from the deacetylation of chitin [7]. Chitosan has been successfully used in many post harvested fruits and vegetables, such as grape, strawberries, berry, jujube and fresh cut lotus root through single coating or comprehensive treatments $[8,9]$. Chitosan can form a film on fruit and vegetable surfaces and reduces respiration rate by adjusting the permeability of carbon dioxide and oxygen. The $\mathrm{NH}_{2}$-group of chitosan may also restrain the propagation of harmful germs, thus effectively controlling fruit decay [10].

Carbon monoxide is a stable diatomic gas molecule. As another gas signal transducer molecule of plant apart from NO, it involved in various physiological and metabolic regulation [11]. Recent research suggested that $\mathrm{CO}$ could enhance the anti-senescence ability of plant leaf, improve the SOD, POD and CAT activities of plant tissue, and reduce the MDA content of fresh cut Chinese rose flower $[12,13]$. In addition, $\mathrm{CO}$ fumigation could prevent the browning of fresh cut lotus root [14]. At present, the researches of the mechanism and the 
physiological effects of $\mathrm{CO}$ on postharvest fruits and vegetables are still not very clear.

In the present work, we treated peaches with $\mathrm{CO}$ gas, chitosan and $\mathrm{CO}$ plus chitosan, and determined the relevant parameters of flesh browning and softening during cold storage. Our objectives were to disclose the possible mechanism of $\mathrm{CO}$ alone and plus chitosan treatments on fruit browning and softening of postharvest peach during cold storage.

\section{Materials and Methods}

\subsection{Materials}

Peach fruit (Prunus persica cv. Hongburuan) were harvested at commercial maturity from local orchard situated in Yaodu district, Linfen city, Shanxi province, China and immediately transported to our laboratory within $2 \mathrm{~h}$ after harvest. Peaches with uniform shape, size, and color, as well as no insect pest and mechanical damage, were selected as materials.

Chitosan (water-soluble, molecular weight of about 200 $\mathrm{kDa}$ and $85 \%$ deacetyl degree) was purchased from $\mathrm{AK}$ Biotech Co., Ltd. (Shandong, China). CO gas with a purity of 99.99\% was purchased from Beijing Huaneng Special Gases Co., Ltd. (Beijing, China). Carbazole and pyrocatechol (analytical grade) were purchased from Sinopharm Chemical Reagent Co., Ltd. (Shanghai, China). Pectin, sodium carboxymethyl cellulose, and galacturonic acid were purchased from Sigma (USA). Other reagents of analytical grade were purchased from Alfa Aesar Company (Tianjin, China).

\subsection{Fruit Treatment}

The peaches were randomly divided into 4 groups, each with $60 \mathrm{Kg}$ fruits. Based on our previous experiments, the first group was immersed in $1 \%$ chitosan solution for $3 \mathrm{~min}$, and then dried under natural wind; the second group was fumigated with $10 \mu \mathrm{mol} / \mathrm{L} \mathrm{CO}$ gas for 2 hours; the third group was firstly fumigated with $10 \mu \mathrm{mol} / \mathrm{L} \mathrm{CO}$ gas for 2 hours, and then dipped into $1 \%$ chitosan solution for $3 \mathrm{~min}$, afterward the peaches were dried under natural wind; the fourth group was untreated jujubes served as control samples. After treated, all samples were stored at $8{ }^{\circ} \mathrm{C}$ and the relevant parameters for the analyses of peaches were measured periodically.

\subsection{Firmness and Water Pectin}

Firmness was determined by a penetrometer (mode GY-4, Mudanjiang, China) with a 8 -mm-long probe with a diameter of $10 \mathrm{~mm}$. 6 fruits were used and two points per fruit were selected to determine the firmness of each replicate sample.

Pulp (5 g) was homogenized in $40 \mathrm{ml}$ of $85{ }^{\circ} \mathrm{C}$ ethanol $(95 \%)$, and the homogenate was incubated for $10 \mathrm{~min}$ at $85{ }^{\circ} \mathrm{C}$, then centrifuged $(10000 \times \mathrm{g})$. The residue was re-extracted with $25 \mathrm{ml}$ of $63 \%$ ethanol at $85^{\circ} \mathrm{C}$ for a further $10 \mathrm{~min}$. The residue was again centrifuged, the water-soluble pectin extracted from the ethanol washed residue. The extract is used to determined water-soluble pectin [15].

\subsection{IB Index}

The degree of IB was visually assessed on the mesocarp surface following a double cut parallel to the axial diameter [16]. The extent of flesh browning was divided into five classes: 0 , no browning; 1 , browning covering $<25 \%$ of the cut surface; 2 , browning covering $\geq 25 \%$ but $<50 \%$ of cut surface; 3 , browning covering $\geq 50 \%$ but $<75 \%$ of cut surface; 4 , browning covering $\geq 75 \%$ of cut surface. The IB index was calculated using the following formula:

IB index $=\sum[($ IB level $) \times$ (number of fruit at the IB level $)] /(4 \times$ total number of fruit in the treatment $)$

\subsection{PG and PE Activities}

PG and PE activities were determined according to the modified method of Zhang et al. (2015) [17]. One unit of PG activity was expressed as nmol of galacturonic acid per min per mg protein, and the PE enzyme activity was expressed as $\mathrm{U} \cdot \mathrm{mg}^{-1}$ protein, one unit activity was calculated as $1 \mathrm{mmol} \mathrm{L}^{-1}$ $\mathrm{NaOH}$ consumed per mg protein per $\mathrm{h}$.

Protein content in the enzyme extracts was estimated using the Bradford (1976) method, with bovine serum albumin as a standard. Specific activity of the enzymes was expressed as units per milligram protein.

\subsection{Total Phenolic Content}

The total phenolic content was measured according to the FolineCiocalteu procedure [18], with little modifications. $5 \mathrm{~g}$ mortar of flesh tissues were extracted three times with $50 \mathrm{~mL}$ of methanol, and centrifuged at $10,000 \mathrm{~g}$ for $10 \mathrm{~min}$ at $4{ }^{\circ} \mathrm{C}$ with centrifuge (Eppendorf 5417R, Hamburg, Germany). The supernatants $(1 \mathrm{~mL})$ were mixed with $1.5 \mathrm{~mL}$ of the FolineCiocalteu reagent. After mixing thoroughly for 6 min, 6 $\mathrm{mL}$ of $1.0 \mathrm{~mol} / \mathrm{L} \mathrm{Na}_{2} \mathrm{CO}_{3}$ solution were added into the mixture. After $90 \mathrm{~min}$ at $25^{\circ} \mathrm{C}$, the absorbance was measured at $765 \mathrm{~nm}$ in a spectrophotometer. The total phenolic content was determined by comparison with the absorbance of gallic acid, which was used at different concentrations as the standard.

\subsection{PAL, PPO and POD Activities}

PAL activity was analyzed by using a modified method of Zhang et al. (2013) [14]. $2 \mathrm{~g}$ flesh of peaches was homogenized in a cold $10 \mathrm{~mL}$ solution of $0.05 \mathrm{~mol} / \mathrm{L}$ sodium borate buffer ( $\mathrm{pH} 8.0$ ) containing $0.5 \mathrm{~g}$ polyvinylpyrrolidone, $5 \mathrm{mmol} / \mathrm{L} \mathrm{2}$-mercaptoethanol and $2 \mathrm{mmol} / \mathrm{L}$ EDTA at $4{ }^{\circ} \mathrm{C}$. The homogenate was centrifuged at $12,000 \mathrm{~g}$ for $20 \mathrm{~min}$ at $4{ }^{\circ} \mathrm{C}$. The supernatant was used as the crude enzyme extract and stored at $4{ }^{\circ} \mathrm{C}$ for the determination. $0.5 \mathrm{~mL}$ of enzyme extract was incubated with assay medium containing $3.5 \mathrm{~mL}$ of 100 mmol/L sodium borate buffers $(\mathrm{pH} 8.7)$ and $1 \mathrm{~mL}$ of 10 mmol/L L-phenylalanine as substrate at $37{ }^{\circ} \mathrm{C}$ for $1 \mathrm{~h}$. The reaction was terminated by adding $0.2 \mathrm{~mL}$ of $6 \mathrm{~mol} / \mathrm{L} \mathrm{HCl}$. PAL activity was measured by change in absorbance at 290 $\mathrm{nm}$. One unit of enzyme activity was defined as the change in absorbance of 0.01 per hour.

POD and PPO activities were measured in pulp tissues 
following the method as described by Zheng et al. (2007) [19]. POD activity was based on the determination of guaiacol oxidation at $470 \mathrm{~nm}$ by $\mathrm{H}_{2} \mathrm{O}_{2}$. The change in absorbance at 470 $\mathrm{nm}$ was followed every $30 \mathrm{~s}$ by a spectrophotometer (UNIC UV-2100, UNIC (Shanghai) Equipment Co. Ltd., China). One unit of POD defined as the amount of enzyme caused 0.01 absorbance increase per min under the conditions of assay. PPO activity was measured by incubating $0.5 \mathrm{ml}$ of enzyme extract to $2.5 \mathrm{ml}$ of buffered substrate $(100 \mathrm{mM}$ sodium phosphate, $\mathrm{pH} 6.4$ and $50 \mathrm{mM}$ Catechol), and then monitoring the change of absorbance at $398 \mathrm{~nm}$. One unit of activity of PPO was defined as the amount of enzyme causing 0.01 absorbance increase per minute under the conditions of assay. The content of protein in crude enzyme extraction was assayed as mentioned above.

\subsection{Statistical Analysis}

Each experiment was repeated three times and the data was processed by analysis of variance (ANOVA) using DPS7.05 statistical software (Refine Information Tech. Co., Ltd, Hangzhou, China). The treatments were compared at $\mathrm{P}=0.05$ using Tukey's test, which indicates the multi-comparison value in each case. The data were expressed as mean \pm standard deviation (SD). Differences at $\mathrm{P} \leq 0.05$ were considered as significant.

\section{Results and Analysis}

\subsection{IB index and Total Phenolic Content}
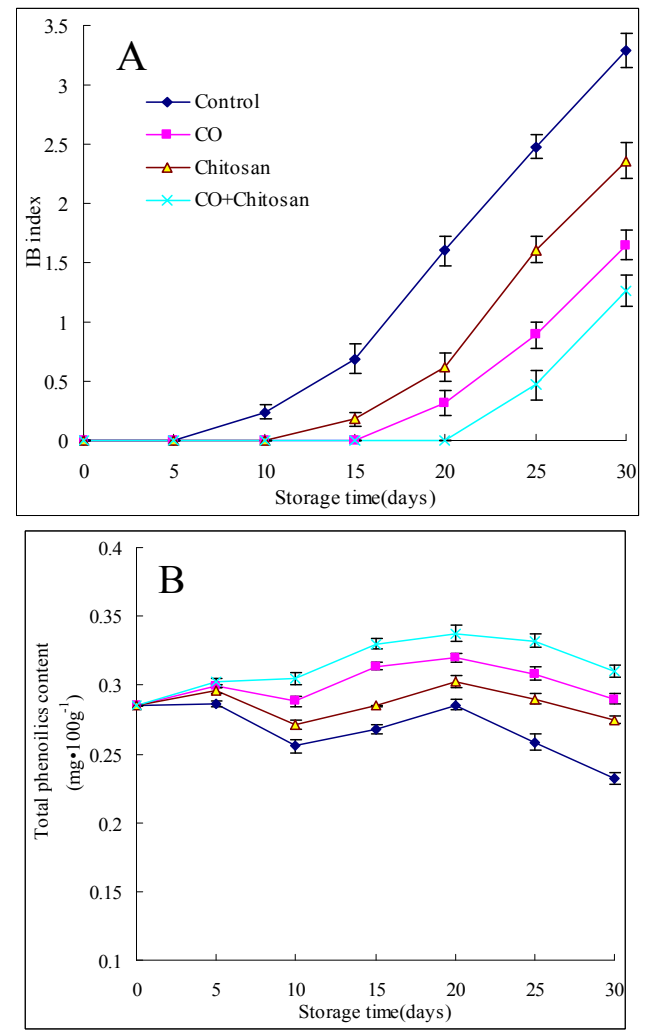

Fig. 1. Effects of different treatments on $I B$ index (A) and total phenoilics content (B) of postharvest peach.
The control fruit showed IB on the 10th day and thereafter the index increased rapidly. CO and chitosan treatment applied separately effectively reduced the development and severity of IB by $50 \%$ and $28 \%$, respectively, after 30 days of storage at $8{ }^{\circ} \mathrm{C}$. However, it was found that the combined application of the two treatments was much more effective than the application of either treatment alone, and significantly $(\mathrm{P} \leq 0.05)$ reduced the development of IB by $62 \%$ after 30 days (Fig. 1A).

During 30 days of storage at $8{ }^{\circ} \mathrm{C}$, total phenoilics of control peaches was significantly lower than that of the treatments. Obviously, $\mathrm{CO}$ and chitosan treatment alone could maintain total phenoilics of flesh at a high level, and treated with $\mathrm{CO}$ was more effective than that with chitosan. The content was significantly $(\mathrm{P} \leq 0.05)$ higher in the combined treatment than that in the separate treatments and control peaches after 10th day (Fig. 1B).

\subsection{PAL, PPO and POD Activities}

PAL activity in the control peach showed a little decrease during the first 10 days, then increased, and declined after 20 days storage. PAL activities in the CO-treated, chitosan-treated and combined treated fruit showed a trend of first increased and then decreased, the peak appeared on 15th, 15th and 20th day, respectively; all treatments maintained PAL activity at a higher level during cold storage(Fig. 2A); and the differences between the treatment with $\mathrm{CO}$, chitosan and $\mathrm{CO}$ plus chitosan were significant $(\mathrm{P} \leq 0.05)$.

PPO activities increased in the control and all the treatments fruit during the storage period. Compared with the control, the treatments with $\mathrm{CO}$, chitosan and $\mathrm{CO}$ plus chitosan obviously inhibited the increase of PPO activities. After 30 days of storage, the activities in the treatments were $75 \%, 84 \%$ and $63 \%$, respectively, of the control (Fig.2B).

POD activities in the control and chitosan-treated peach fruit increased slightly during the first 15 days; for the treatments with $\mathrm{CO}$ or plus chitosan, the activities seemed little decreased after 10 days storage; and it were increased thereafter in all treatments and the control peach fruit. All treatment slowed down the changes of POD activity; however, the treatment with $\mathrm{CO}$ plus chitosan was most effective in all treatments, and the activity was only $67 \%$ of the control at day 30 (Fig. 2C).

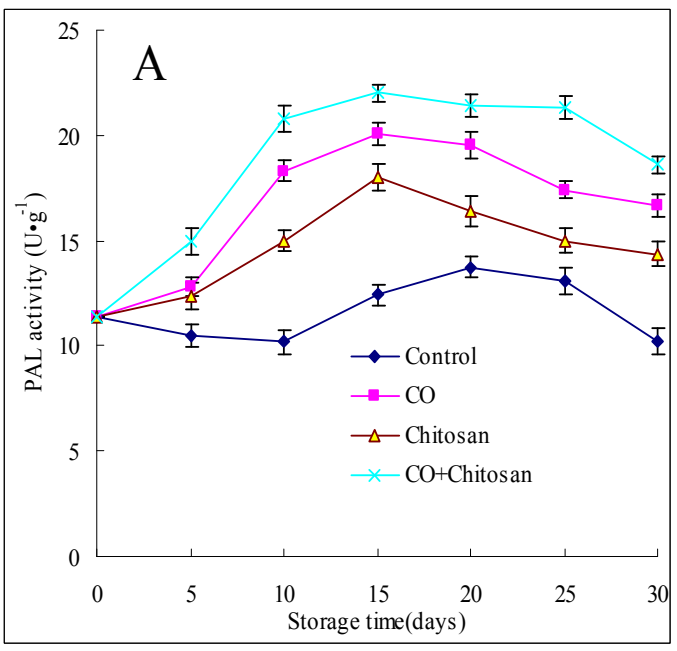



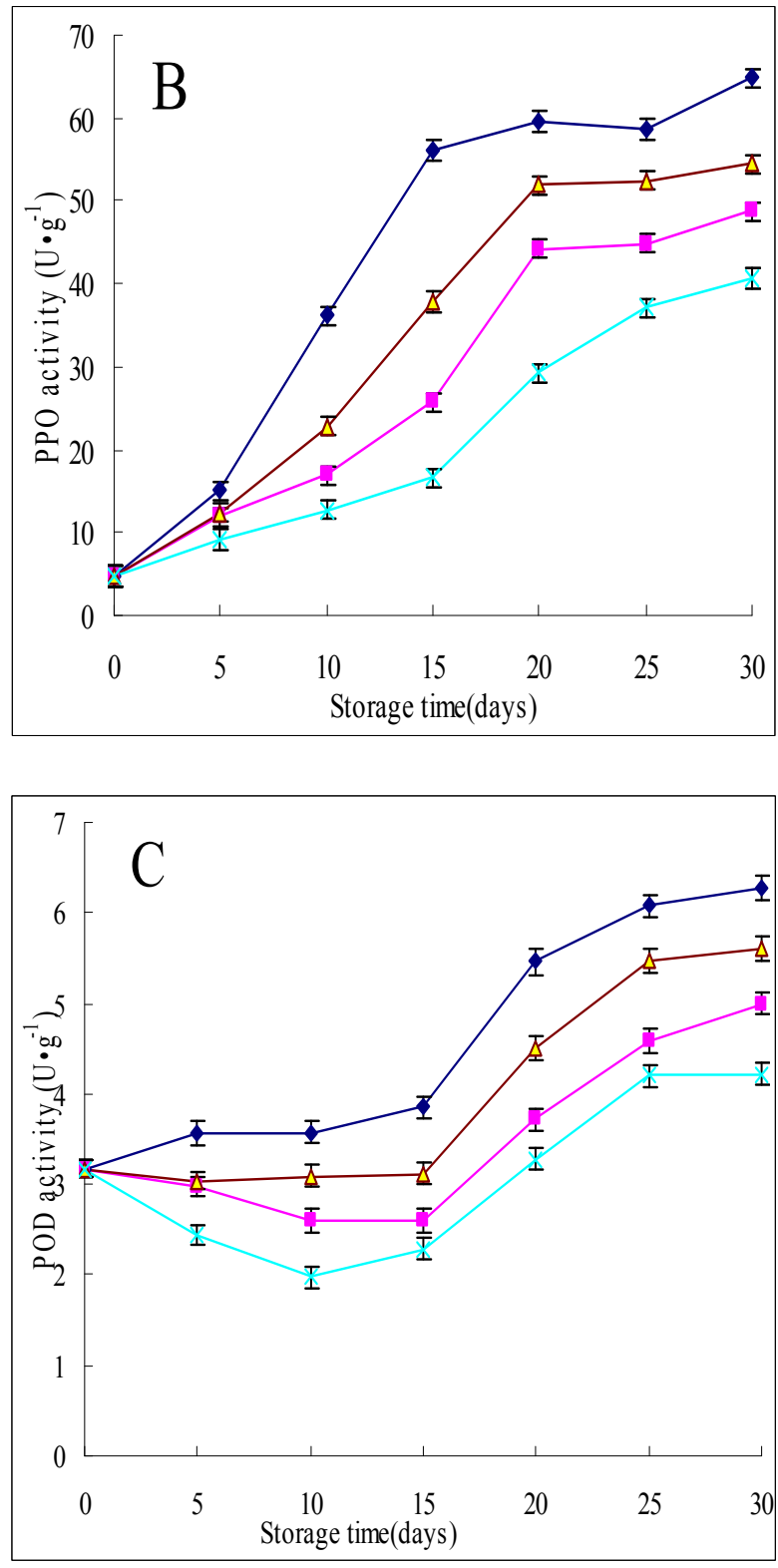

Fig. 2. Effects of different treatments on PAL (A), PPO (B) and POD (C) activities of postharvest peach.

\subsection{Firmness and Water Soluble Pectin Content}

Fruit firmnesses of all treatments fruit were declined during the whole storage period. But for the control firmness showed a little increase after 20 days storage (Fig. 3A). Firmness of the treatments (with $\mathrm{CO}$, chitosan, and $\mathrm{CO}$ plus chitosan) fruit were significantly higher compared to the control before 25 , 20 and 30 , respectively, days storage $(\mathrm{P} \leq 0.05)$.

Water soluble pectin content in the control peaches increased in the first 20 day, and then decreased (Fig. 3B). Water soluble pectin content in all treatments peaches were increased during storage time and it were lower than in the control. Obviously, the combined treatment was more effective than other.
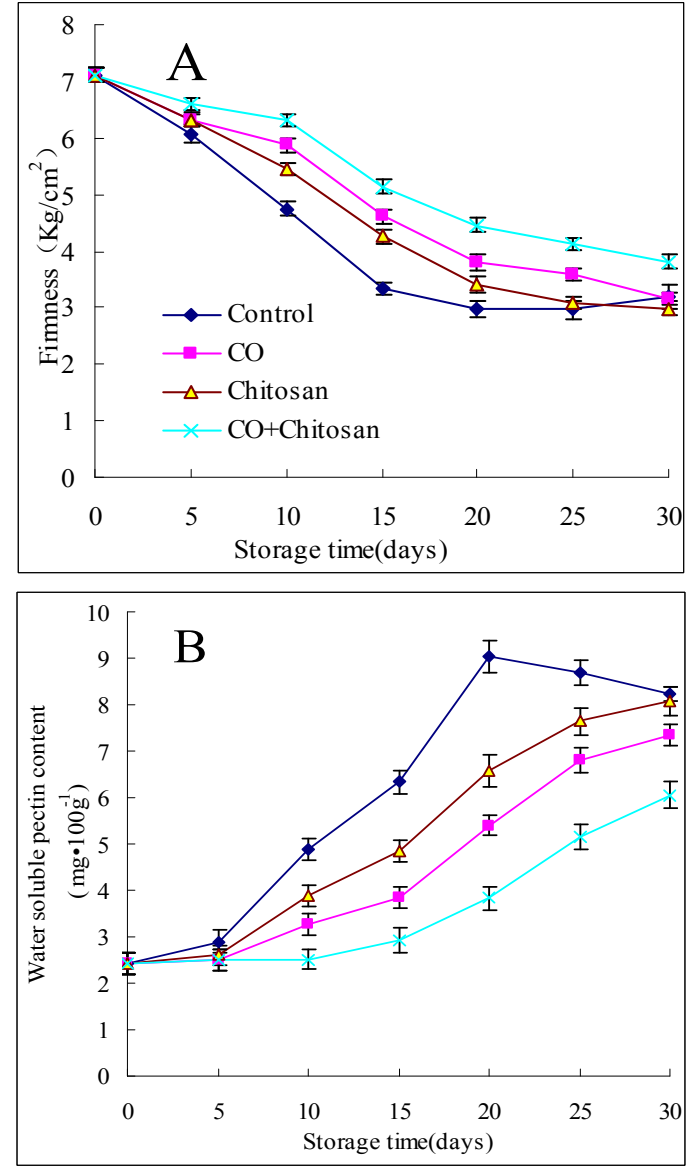

Fig. 3. Effects of different treatments on firmness (A) and water soluble pectin (B) content of postharvest peach.

\subsection{PE and PG Activities}

Generally, PE activities in the control, as well as in the treatments peaches increased with the extension of storage time (Fig.4A). However, all treatments could distinctly inhibit the increase of PE activity in the flesh of peach. PE activity in combined treatment peach was significantly lower than other treatments and the control after 5 day, was $37 \%$ lower than in the control.

PG activity in the control and treatment with chitosan fruit, as shown in figure 4B, firstly ascended and then declined, and the peaks appeared at day 15 and 20, respectively. The activities in the CO-treated and combined treated peaches gradually increased during storage time. The treatment with $\mathrm{CO}$, chitosan and $\mathrm{CO}$ plus chitosan could inhibit the change of PG activity, and the combined treatment was more effective than with either treatment alone.

\section{Discussion}

\subsection{Effect of $C O$ and Chitosan on Flesh Browning of Postharvest Peach}

Peaches are easy softening, browning and rot after harvested at room temperature. However, Peaches are very sensitive to low temperature and exhibit chilling injury after 
long periods of refrigeration. The main symptoms of chilling injury are leathered flesh or internal browning and flesh mealiness that lead to a dry, grainy sand-like texture [3]. Carbon monoxide enhances the chilling tolerance of recalcitrant Baccaurea ramiflora seeds via nitric oxide-mediated glutathione homeostasis [20].
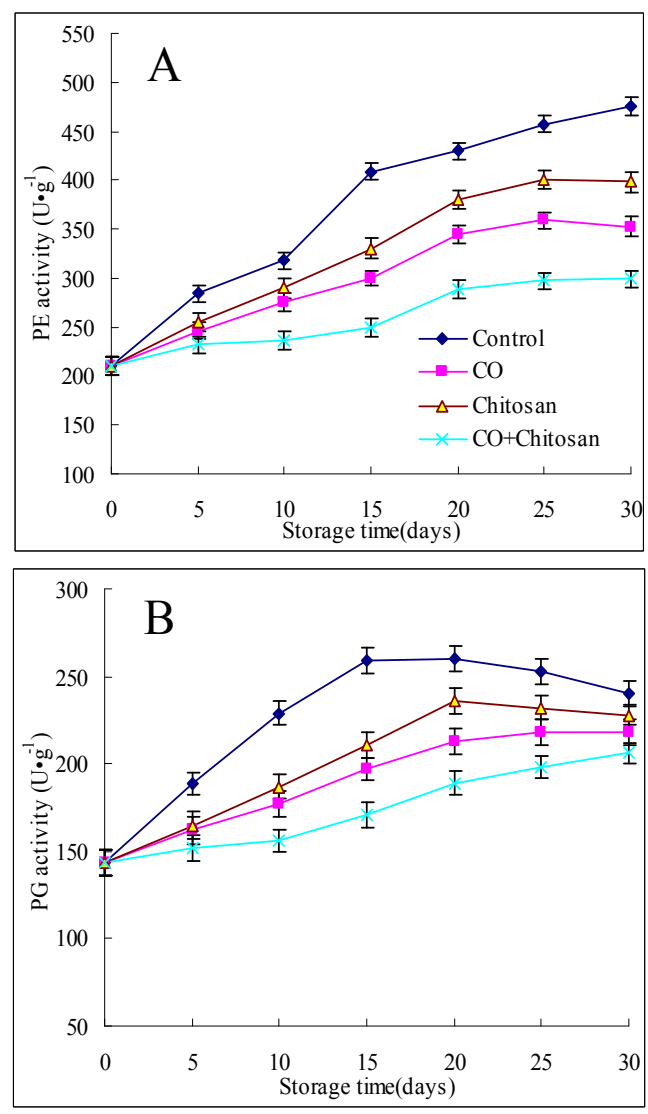

Fig. 4. Effects of different treatments on $P E(A)$ and $P G(B)$ activities of postharvest peach.

Our results showed that the symptom of flesh browning emerged at 10th day after cold storage in the untreated 'Hongburuan' peach fruit, and IB index was increased with the extension of storage time. The treatments of $10 \mu \mathrm{mol} / \mathrm{L} \mathrm{CO}$ and $1 \%$ chitosan alone could inhibit the increase of flesh browning, and IB index in the combined treatment was lower than other treatment and control. Flesh browning was one of the main CI symptoms and oxidation of phenolic substrates by polyphenol oxidase (PPO) was thought to be a major cause of the discoloration in many fruits [3]. In general, phenolic compounds with regards to their antioxidant capacity were accumulated in plant tissue under cold stress [21]. Thus especial attention should be paid to the dual action of phenols of the antioxidant activity and oxidative browning. Peroxidase was one of the main antioxidant enzymes and catalyzed the polymerisation of phenolic compounds as well [22], and was usually estimated as main factor to illustrate the changes of phenol metabolism.

Internal browning of fruit is probably related to the increase in PPO and POD activities, which could oxidize phenolic compounds to quinone or quinine-like compounds, finally appearing as polymerized brown pigments [5]. Qi et al. (2011) [23] reported that chitosan-coating treatment Extended the shelf-life of Fresh-cut 'Fuji' apples by controlling its cut-surface browning. Zhang et al. (2013) [14] found that CO retarded the browning of fresh-cut lotus by inhibited PPO and POD activities, at the same time $\mathrm{CO}$ also promoted PAL activity and all of these were conducive to maintaining the quality and shelf life. Our results showed that $\mathrm{CO}$ alone of combined with chitosan could induced PAL activity, increased the total phenoilics, which could enhance the resistance to cold damage and strengthen the tolerance for chilling injury. In addition, $\mathrm{CO}$ reduced PPO and POD activity, and inhibited enzymatic browning in flesh of peach.

\subsection{Effect of $\mathrm{CO}$ and Chitosan on Fruit Softening of Postharvest Peach}

Peach fruits softening characterized as firmness decline in ripening process was associated with cell wall modification. Polygalacturonase (PG) is one of the pectin-degrading enzymes and plays a central role in ripening process [24]. Pectin methyl esterase (PME), catalyzing hydrolysation of methyl ester group of pectin, is a key control enzyme for both assembly and disassembly of pectin network [25] by determining tissue integrity during fruit senescence. Zhou et al (2000a) [26] found an increase in PE activity and inhibition of PG in cold stored peach fruit relative to their activities in normally ripening fruit. The occurrence of flesh mealiness and woolliness in peaches or nectarines has been found to be associated with imbalance of PG and PME activities [27]. Firmness of untreated fruit did not decrease after 15 days cold storage, and a little increased at day 30 , but for treated fruit firmness reduced in whole storage period, but the decline was not too big, the firmness decreased by $50 \%$ ( from 7.12 to 3.19 $\mathrm{Kg} / \mathrm{cm}^{2}$ ), obviously, 'hongburuan' peach was a variety more like non-melt peach. The water soluble pectin in the control fruit increased before 20th day then decreased. CO, chitosan or combined treatment retarded the increase of water soluble pectin in the fruit but not inhibited the decline of flesh firmness, and peaches softened as usual. The treatments were effective to resist the chilling injury refer to the condition of flesh browning. The further research result showed that the treatment inhibited the increase of PE and PG activities as well maintain the balance between PE and PG activity which is necessary for fruit softening [28].

\section{Conclusion}

$\mathrm{CO}(10 \mu \mathrm{mol} / \mathrm{L})$ significantly delayed the internal browning of peach fruit, and the effect was enhanced in combination with chitosan $(1 \%, \mathrm{w} / \mathrm{w})$. The treatment with $\mathrm{CO}$ and chitosan reduced the increase of PPO and POD activities, maintained PAL activity and total phenoilics content at a higher level. And, it also retarded the increase of PE, PG activities and water soluble pectin content, inhibited the decline of flesh firmness as well as sustained the balance of PG and PE activities. The combined treatment with $\mathrm{CO}$ and chitosan can be effective in reducing browning and softening of peach fruit and inhibited 
chilling injury during cold storage.

\section{Acknowledgements}

This work was supported by project of the National Natural Science Foundation of China under grant no. 31101359, by Program for the Innovative Talents of Higher Learning Institutions of Shanxi (2012), and by project for the 131 Leading Talent of Higher Learning Institutions of Shanxi no. 447(2013).

\section{References}

[1] Byrne DH (2002). Peach breeding trends. Acta Hortic. 592: 49-59.

[2] Tareen M J, Abbasi N A, Hafiz I A(2012). Postharvest application of salicylic acid enhanced antioxidant enzyme activity and maintained quality of peach cv. 'Flordaking' fruit during storage. Scientia Horticulturae, 142: 221-228

[3] Lurie S, Crisosto C H (2005). Chilling injury in peach and nectarine. Postharvest Biology and Technology,37: 195-208.

[4] Ebel R C, Woods F M, Himelrick D (1999). Effect of UV-C on ripening and postharvest quality of peach. HortScience, 34:504.

[5] Jin P, Zheng Y H, Tang S S, Rui H J, Wang C Y (2009). A. combination of hot air and methyl jasmonate vapor treatment alleviates chilling injury of peach fruit. Postharvest Biology and Technology, 52: 24-29

[6] Girardi C L, Corrent A R, Lucchetta L, et al. (2005). Effect of ethylene, intermittent warming and controlled atmosphere on postharvest quality and occurrence of woolliness in peach (Prunus persica cv. Chiripa) during cold storage. Postharvest Biol. Technol, 38: 25-33.

[7] Carlson R P, Taffs R, Davison W M, \& Stewart P S (2008). Anti-biofilm properties of chitosan coated surfaces. Journal of Biomaterials Science: Polymer Edition, 19: 1035-1046.

[8] $\mathrm{Vu} \mathrm{K} \mathrm{D,} \mathrm{Hollingswort} \mathrm{R} \mathrm{G,} \mathrm{Leroux} \mathrm{E,} \mathrm{et} \mathrm{al.} \mathrm{(2011).}$ Development of edible bioactive coating based on modified chitosan for increasing the shelf life of strawberries. Food Research International, 44:198-203.

[9] Wang S Y, \& Gao H (2013). Effect of chitosan-based edible coating on antioxidants, antioxidant enzyme system, and postharvest fruit quality of strawberries (Fragaria $\mathrm{x}$ aranassa Duch.). LWT - Food Science and Technology, 52: 71-79.

[10] Devlieghere F, Vermeulen A, \& Debevere J (2004). Chitosan: Antimicrobial activity, interactions with food components and applicability as a coating on fruit and vegetables. Food Microbiology, 21:703-714.

[11] García-Mata C, Lamattina L (2013). Gasotransmitters are emerging as new guard cell signaling molecules and regulators of leaf gas exchange. Plant Science, 201-202: 66-73.

[12] Huang J J, Han B, Xu S, Zhou M X \& Shen W B (2011). Heme oxygenase-1 is involved in the cytokinin-induced alleviation of senescence in detached wheat leaves during dark incubation. Journal of Plant Physiology, 168(8): 768-775.
[13] Ling T F, Zhang B, Lin J S, Liu H, et al. (2006). Effects of carbon monoxide on vase life and antioxidative metabolism in the cut rose flower. Acta Horticulturae Sinica, 33(4): 779-782. (In Chinese)

[14] Zhang S Y, Yu Y W, Xiao C L, et al. (2013). Effect of carbon monoxide on browning of fresh-cut lotus root slice in relation to phenolic metabolism. LWT - Food Science and Technology, 53(2): 555-559.

[15] Ketsa S, Daengkanit T (1999). Firmness and activities of polygalacturonase, pectinesterase, $\beta$-galactosidase and cellulase in ripening durian harvested at different stages of maturity. Scientia Horticulturae, 80: 181-188

[16] Cao S F, Hu Z C, Zheng Y H, Lu B H (2010). Synergistic effect of heat treatment and salicylic acid on alleviating internal browning in cold-stored peach fruit. Postharvest Biology and Technology, 58: 93-97.

[17] Zhang SY, Shi Y, Deng B (2015). Exogenous carbon monoxide treatment delayed the ethanol metabolism and fruit softening of postharvest jujube. Asian Journal of Agriculture and Food Sciences, 3 (2):196-204.

[18] Xiao C L, Zhu L W, Luo W, et al. (2010). Combined action of pure oxygen pretreatment and chitosan coating incorporated with rosemary extracts on the quality of fresh-cut pears. Food Chemistry, 121(4): 1003-1009.

[19] Zheng X L, Tian S P, Meng X H, Li B Q (2007). Physiological and biochemical responses in peach fruit to oxalic acid treatment during storage at room temperature. Food Chemistry, 104: 156-162.

[20] Bai X G, Chen J H, Kong X X, et al. (2012). Carbon monoxide enhances the chilling tolerance of recalcitrant Baccaurea ramiflora seeds via nitric oxide-mediated glutathione homeostasis. Free Radical Biology and Medicine, 53:710-720

[21] Pennycooke J C, Cox S, \& Stushnoff C (2005). Relationship of cold acclimation, total phenolic content and antioxidant capacity with chilling tolerance in petunia (Petunia_hybrida). Environmental Experimental Botany, 53: 225-232.

[22] Blokhina O, Virolainen E, \& Fagerstedt K V (2003). Antioxidants, oxidative damage and oxygen deprivation stress: A review. Annals Botany, 91: 179-194.

[23] Qi H P, Hu WZ, Jiang AL, et al. (2011). Extending shelf-life of Fresh-cut 'Fuji' apples with chitosan-coatings. Innovative Food Science and Emerging Technologies, 12: 62-66

[24] Wakabayashi, K. (2000). Changes in cell wall polysaccharides during fruit ripening. Journal of Plant Research, 113: 231-237.

[25] Willats W G T, McCartney L, Mackie W, \& Knox J P (2001). Pectin: Cell biology and prospects for functional analysis. Plant Molecular Biology, 47: 9-27.

[26] Zhou H W, Ben-Arie R, Lurie S (2000a). Pectin esterase, polygalacturonase and gel formation in peach pectin fractions. Phytochemistry, 55:191-195

[27] Zhou H W, Lurie S, Lers A, et al.(2000b). Delayed storage and controlled atmosphere storage of nectarines: two strategies to prevent woolliness. Postharvest Biol. Technol., 18:133-141.

[28] Manganaris G A, Vasilakakis M, Diamantidis Gr, Mignani I (2006). Cell wall physicochemical aspects of peach fruit related to internal breakdown symptoms. Postharvest Biology and Technology, 39: 69-74. 